\title{
СОЦИОКУЛЬТУРНЫЕ ФАКТОРЫ ФОРМИРОВАНИЯ ПРОФЕССИОНАЛЬНОЙ ИДЕНТИЧНОСТИ (СОЦИАЛИЗАЦИЯ И КОРПОРАТИВНАЯ КУЛЬТУРА КАК СУЩЕСТВЕННЫЕ ФАКТУРЫ ФОРМИРОВАНИЯ ПРОФЕССИОНАЛЬНОЙ ИДЕНТИЧНОСТИ)
}

\section{SOCIOCULTURAL FACTORS \\ IN THE FORMATION OF PROFESSIONAL IDENTITY (SOCIALIZATION AND CORPORATE CULTURE AS ESSENTIAL TEXTURES OF THE FORMATION OF PROFESSIONAL IDENTITY)}

\section{K. Budaud}

Summary: This article analyzes socialization and corporate culture as essential invoices in the construction of professional identity, we will first try to talk about socialization and in particular professional socialization, and also to explain what is involved. corporate culture and how it has a direct influence on the formation of professional identity. all of this we propose under a research result obtained by qualitative survey, observation, interviews and group discussion.

Keywords: socialization, corporate culture, professional socialization, identity, professional identity, professional identity formation.

\section{Введение}

$\mathrm{y}$ читывая большое значение, мы придаем концепции профессиональной идентичности. Сначала мы попытаемся поговорить о социализации и, в частности, о профессиональной социализации, это тема, которая призвана объяснить различные отношения и поведение в компаниях, и мы также обсудим различные уровни и типы социализации. Так же мы постараемся объяснить и уточнить, что такое айдентика, ее конструкция, место работы в айдентике, а также влияние культуры компании на формирование профессиональной идентичности. (GOHIER 2000)

Социализация - это интерактивный и разнонаправленный процесс, он предполагает взаимодействие между социализированными и социализаторами, это процесс конструирования идентичности, он включает в себя постоянные пересмотры во всех подсистемах социализации, как написано Першерон «Социализация принимает форму точки встречи. событие или компромисс между потребностями и желаниями человека и ценностями различных групп, с которыми он вступает в контакт». Концепция социализации занимает централь-

\author{
Будауд Карим \\ Аспирант, Казанский федеральный университет, Казань \\ K-Budaud@stud.kpfu.ru
}

Аннотация: В данной статье анализируется социализация и корпоративная культура как важнейшие составляющие построения профессиональной идентичности. Сначала мы попытаемся поговорить о социализации и, в частности, о профессиональной социализации, а также объяснить, что такое корпоративная культура и как она имеет прямое влияние на формирование профессиональной идентичности. Все это мы предлагаем в результате исследования, полученного путем качественного опроса, наблюдения, интервью и группового обсуждения.

Ключевые слова: социализация, корпоративная культура, профессиональная социализация, личность, профессиональная идентичность, формирование профессиональной идентичности.

ное место в теории Эмиля Дюркгейма, он объясняет, что именно в процессе социализации человек принимает нормы и ценности, выработанные в обществе. В контексте этого исследования размышления DURKHEIM о социализации интерпретируются как приобретение знаний, идей и обучения, которые позволяют человеку ориентироваться и интегрироваться в рынок труда и, таким образом, формировать профессиональную идентичность. К. ДУБАР рассматривает концепцию социализации как установленный во времени процесс, посредством которого строятся социальные и профессиональные идентичности. По его словам, «идентичность является результатом как стабильного и временного, индивидуального и коллективного, субъективного и объективного, биографического и структурного, различных процессов социализации, которые совместно создают индивидов и определяют институты». Гай Рошер, со своей стороны, определяет социализацию как «... Процесс, посредством которого человеческая личность изучает и усваивает все в течение своей жизни социокультурные элементы своего окружения, интегрирует их в структуру своей личности под влиянием опыта. и значительными социальными агентами и, таким образом, приспосабливается к социальной среде, в которой она должна жить. 
Он объясняет, что социализация - это процесс, который не приобретается раз и навсегда, но он развивается и обновляется по мере того, как человек проходит через опыт.

\section{Сочиализашия, прочесс построения идентичности}

Социализация - это важный процесс формирования идентичности, который питается сложными отношениями между человеком и окружающей его социальной средой. Следовательно, идентичность не является врожденной, она выстраивается на разных этапах процесса социализации человека, а также через взаимодействия, опыт и жизненные пути. Социализация будет касаться как области психологии, так и области социологии. Первичная социализация относится к области психологии и касается периода детства: семьи, школы, взаимодействия с другими людьми и влияния средств массовой информации, которые помогают структурировать социальную личность ребенка личность конструируется. На этой фазе первичной социализации человек включает данные, вещи существ, составляющих его внешнюю среду, приспосабливается к изменениям и прогрессу в построении своей личности и, следовательно, выстраивает свою собственную идентичность. PIAGET объясняет процесс первичной или детской социализации как психический процесс, который состоит из ассимиляции и включения внешнего мира. Также вторичная социализация позволяет человеку, который уже сформировал свою личность, интегрироваться в определенную группу, такую как: компания, ассоциация, политическая партия ..., путем приобретения определенных норм и ценностей, что позволяет человеку иметь определенное социальное положение и конструкция среды. Вторичная социализация средство в соответствии с ALPE. Ив «Продолжение процесса социализации в зрелом возрасте, в основном в мире работы и в семье»

Действительно, построение личной, социальной и профессиональной идентичности является результатом как психического, так и ментального процесса, а также интернализации внешнего мира индивидом в процессе первичной социализации. Переход от первичной социализации к вторичной социализации не означает отношений непрерывности, но может быть разрывом.

\section{Профессиональная сочиализачия}

Процесс социализации является важным понятием в проблематике интеграции и формирования профессиональной идентичности, доступа к занятости, эволюции работы от одной должности к другой, представляет собой различные этапы социализации и важного построения идентичности. Социализация - это процесс постоянного взаимодействия между человеком и различными социальными институтами, среди которых есть и компания. Доступ к миру труда и развитие в сфере занятости составляют индивидуальные источники построения его идентичности.

В работе есть несколько факторов социализации.

Среди этих требований - социализация через обучение, которая является фактором и моментом профессиональной социализации и может сопровождать человека на протяжении всей его карьеры. И функционалисты, и интеракционисты подчеркивали важность социализации новобранцев, чтобы они принимали ценности, которыми руководствуется в профессиональной практике, и вырабатывали ожидаемое поведение.( Эдгар Шейн1985)

Существует также социализация сверстников, при которой обмены между сверстниками важны в жизни человека, формируют его личность и способствуют возникновению идентичности. Повторные обмены мнениями с коллегами играют важную роль в построении и подтверждении идентичности. Человек на своем рабочем месте поддерживает отношения со своими коллегами, он выполняет совместную работу, коллегиальность, которая порождает чувство принадлежности к профессиональной группе. Таким образом, отношения с коллегами позволяют ему чувствовать, что он подходит к работе как «коллектив», и устанавливает коллективное «нас» на основе общих интересов, общих ценностей и идентичности. Чувство принадлежности к профессиональной группе, как указали GOHIER и другие, может развиваться путем формулирования общих целей в рамках общего (образовательного) проекта, например, но также путем осуществления общих (педагогических) практики, а также встретившиеся трудности. (GOHIER 2000)

Фактически, столкнувшись с масштабом и разнообразием проблем и трудностей, возникающих на конкретной работе, человек не может подходить к своей профессии в одиночку, он вынужден делиться своим опытом со своими коллегами.

Социализация через отношения - это еще один счет в отношениях, требующий первостепенной важности в построении идентичности человека. Это также считается динамическим поддержанием сохранения идентичности. Работа - это прежде всего быть частью отношений, отношений обмена. Руководители, вовлеченные в отношения, обычно демонстрируют ценный образ самих себя, который они считают своей профессиональной идентичностью. Работа менеджера, несомненно, представляет собой интерактивную работу или отношения с другими, позволяющие ему обрести важное измерение своей личности. В этом смысле Сет Готье показал, что отношения играют ключевую роль в формировании профессиональной идентичности. (GOHIER 2000)

\section{Корпоративная культура, инструмент управления идентичностью}


Под корпоративной культурой мы подразумеваем все способы мышления, чувств и действий, общие для членов одной организации. Таким образом, корпоративная культура соответствует образу мышления, системе ценностей и правил, относительно организованной, которую разделяют все участники компании. «Культура это то, что делает каждую компанию уникальной, нет двух полностью одинаковых компаний. две компании могут следовать одной и той же стратегии, иметь одинаковые структуры, использовать одни и те же методы управления, тем не менее, каждая из них имеет свою собственную культуру, которая отличает их друг от друга. «(GOHIER 2000)

Культура является важным инструментом управления, вошел мир 1980 - х годах, это вовсе не означает до того как компании не культуры, это потому это только то становится важным инструментом для управления. Корпоративная культура - это не объект, который руководство может формировать по своему усмотрению. Для менеджеров культура - это скорее организационная реальность, которую они должны принимать во внимание, это ресурс, которым они могут воспользоваться. Менеджеры не могут управлять культурой, но вместо этого они управляют с культурой.

\section{Корпоративная культура, главный вектор ицентификашии}

Компания действительно является местом социализации и, следовательно, построения идентичности. Сэнсаулиё объясняет, что компания представлена как «центральное социальное место» и «фокус производства идентичности». Фактически, это не может быть сведено к «театру» для игр актеров, а, напротив, характеризуется склонностью к производят ценности, нормы, способы мышления, системы интерпретации, системы убеждений, представлений и знаний - все это категории, относящиеся к умственной деятельности. Среди этих категорий социальные представления и символизм (ритуалы, мифы, рассказы, легенды) могут быть выделены как лежащие в основе процесса создания смысла.( АЛЬПЕ, 2007)

В процессе репрезентации генерируются и передаются значения. Согласно Jodelet (1989), представление или представление самого себя соответствует мыслительному акту, посредством которого субъект соотносится с «объектом» для создания смысла. Объектом мо- жет быть человек, вещь, материальное, психическое или социальное событие, природный феномен, идея или теория, или комбинация нескольких из этих элементов. Это может быть как реальным, так и воображаемым или мифическим, но это всегда необходимо. Таким образом, в то время как представление позволяет увидеть этот объект, он находится на своем месте. Она заставляет его присутствовать, когда он далеко или отсутствует. Следовательно, это мысленный перевод объекта, который он символически восстанавливает. (Jodelet 1989)

Именно благодаря созданию этих более или менее согласованных систем значений, представлений и символов формируются взаимодействие и социальное действие. Другими словами, сообщения и символы, связанные с культурой, передаются человеку формальными и неформальными средствами, которые подталкивают человека к созданию в его собственной психике представления о компании. Механизм интеграции осуществляется на основе приверженности ценностям компании. Большим преимуществом этого механизма является то, что индивидуальный проект сливается с корпоративным проектом. Чтобы добиться успеха и получить максимальную пользу, человек должен делать все возможное, чтобы служить своему бизнесу. Таким образом, идентификация проявляется в глубокой привязанности к компании и чувстве собственной значимости. Эта идентификация является мотивирующим фактором. (ДУБАР Клод 2000)

\section{Культурный подхоА К профессиональной иАентичности}

Для этого подхода все модели поведения и отношения на работе не развиваются случайным образом, но именно культура, сформированная в компании, которую он сформировал, организационная культура, которая представлена в форме норм и правил, а также ценностей, помогает определить личности рабочих. В этом смысле R. SAINSAULIEU продемонстрировал в 1960 году, что доступ к профессиональной идентичности пронизан культурным аспектом. SAINSAULIEU показывает, что трудовые отношения могут формировать профессиональную идентичность. Он рассматривал идентичность с точки зрения рабочих отношений. Масштабные исследования (более 200 интервью и 8000 анкет) были проведены с 1960-х годов на рабочих, служащих, техниках и менеджерах, эти сотрудники работают в различных секторах (эклектические материалы, механика, химическое
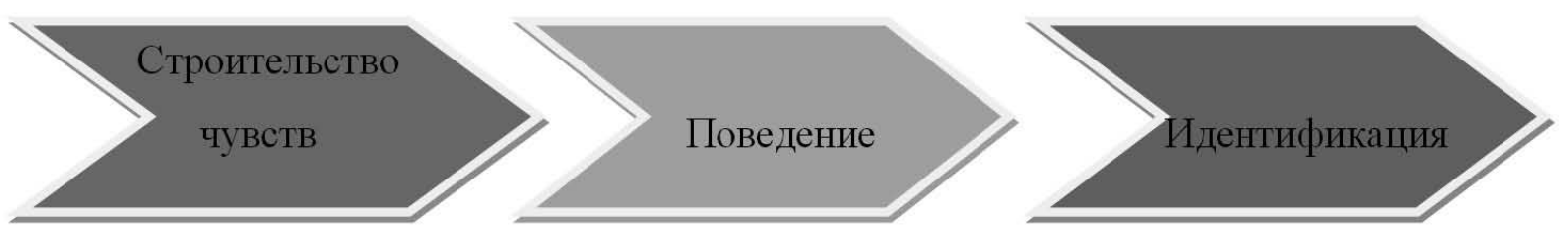

Рис. 1. Процесс идентификации в компании 
страхование ...). SAINSAULIEU выделяет типы культуры взаимоотношений на работе. (Sainsaulieu P., 1985)

Эти исследования позволили ему определить четыре модальности норм и ценностей, четыре образа идентичности на работе, четыре способа быть с коллегами и лидерами, все разные (слияние-сходство-переговорыотказ от отношений).

\section{Профессиональная ихентификашия по принацлежности к компании}

Принадлежность к компании также является вектором идентичности, и отношение к компании позволяет этой идентичности существовать. Человек почти неосознанно интегрирует жесты, слова, принципы, ценности или даже жаргонизмы компании, в которой он работает. Однако, согласно OSTEY (2008), компания должна гарантировать, что идентификация продолжает существовать, потому что она, кажется, обеспечивает качество и сплоченность. Таким образом, идентификация людей с компанией влечет за собой положительные или отрицательные последствия. Если люди идентифицируют себя со своей организацией, это уменьшает конфликты между группами, позволяет развивать более совместное поведение и повышает их мотивацию.

\section{Обсужление результатов}

Постараемся проанализировать некоторые из полученных нами результатов.

Результаты подтверждают, что большинство работников с 85\% обеспечивают соблюдение внутренних правил своей компании, и это для того, чтобы обеспечить бесперебойную работу и не вызывать дисфункции, как один из них указывает нам с 11-летним опытом: «Несоблюдение нормативных требований квалифицируется как нарушение профессиональной этики.» Из ответов, полученных нами в ходе наших опросов, мы замечаем, что большинство сотрудников меняют свое поведение на работе и устраняют поведение, которое не принимается компанией, они пытаются дать представление, которое больше всего соответствует имиджу компании.

Из этих результатов мы видим, что корпоративная культура, то есть то, как мы работаем ежедневно, влияет на поведение сотрудников. Как только они приходят в компанию, они неосознанно принимают установки и поведение, которые распространены в компании и предпочитаются большинством. Один из руководителей даже прокомментировал этот вопрос, сказав: «Когда мы переступаем порог компании, мы находимся в профессиональной жизни, мы бессознательно меняем свое от-

P. SAINSAULIEU, идентичность на работе

\begin{tabular}{|l|l|l|l|l|}
\multicolumn{1}{|c|}{ Общительность } & \multicolumn{1}{|c|}{ Слияние } & \multicolumn{1}{c|}{ Переговоры } & \multicolumn{1}{c|}{ Близость } \\
\hline Реляционная поведение & Единодушие & $\begin{array}{l}\text { Солидарность и демократи- } \\
\text { ческое соперничество }\end{array}$ & Сепаратизм & Индивидуализм \\
\hline позиция Актер & $\begin{array}{l}\text { Коллективный актер через } \\
\text { борьбу }\end{array}$ & Сильный эксперт-актер & Индивидуальный актер & Неактер \\
\hline Типы удостоверений & Класс & Работа & Путь & Без работы \\
\hline
\end{tabular}

Таблица 2.

Распределение выборки в соответствии с уважением внутренними регламентами

\begin{tabular}{|c|c|c|}
\hline $\begin{array}{c}\text { соответствии суважением } \\
\text { внутренними регламентами }\end{array}$ & КОЛИЧЕСТВО ОБРАЗЦОВ & $(\%)$ \\
\hline ВСЕ ВРЕМЯ & 108 & $17 \%$ \\
\hline ВРЕМЕНИ N ВРЕМЕНИ & 22 & $00 \%$ \\
\hline ВОВСЕ НЕТ & 00 & $100 \%$ \\
\hline ВСЕГО & 130 & $17 \%$ \\
\hline
\end{tabular}

Распределение выборки по изменению поведения на работе

Таблица 3.

\begin{tabular}{|c|c|c|}
\hline изменение поведения на работе & КОЛИЧЕСТВО ОБРАЗЦОВ & (\%) \\
\hline ДА & 110 & $15 \%$ \\
\hline НЕТ & 20 & $100 \%$ \\
\hline ВСЕГО & 130 & $15 \%$ \\
\hline
\end{tabular}


ношение. »[Самир, инженер-технолог, 45 лет.]

Коллективная работа - это мотив, который участвует в построении профессиональной идентичности, необходимости принадлежать к профессиональной группе. Это помогает создать хороший рабочий климат и, учитывая коммуникативный дух нашего образца, облегчает и стимулирует коллективную работу. И согласно классификации SAINSAULIEU (Sainsaulieu P., 1985), эти сотрудники являются частью идентичности типа переговоров: «Эта культура характеризуется, прежде всего, большим эмоциональным и когнитивным богатством демократического типа.»

Вторая категория - это сотрудники, которые предпочитают не поддерживать отношения с коллегами и отказываются идентифицировать себя с другими.

Наконец, мы можем считать, что групповая работа это ценность, которая обеспечивает лучшую интеграцию в среду профессионального взаимодействия.

Анализируя эти результаты, мы видим, что категория, которая считает их отношения важными, - это сотрудники, которые рассматривают межличностные отношения как актив, и в соответствии с классификацией личности SAINSAULIEU, сотрудники имеют переговорную идентичность, которая определяется важностью реляционных сетей в профессиональная жизнь. Это один из факторов, который их мотивирует и поддерживает работу.
Анализируя эти результаты, мы видим, что наши респонденты устанавливают отношения, основанные на обмене информацией, участии в управлении работой, как объяснил нам менеджер с 7-летним опытом: «обмен идеями и соучастие в решении проблем. «[Набиль, научный сотрудник, 38] У этой категории очень тесные отношения со своим лидером, который ведет к командному духу, основанному на достижении целей. Интеграция руководителей в его задачи способствует групповой работе, это метод, который лидер принимает, чтобы стимулировать руководителей, ответственных за свои функции.

\section{Обсу»кение}

Профессиональная идентичность может быть представлена как набор, состоящий из двух компонентов. Первый, на конкретном уровне, состоит из первоначальной идентичности, полученной (до входа в социальное пространство компании), определенной в результате академической подготовки и технической.

Второй, по сути, состоит из совокупности профессиональных знаний с момента прихода в компанию. Благодаря техническому опыту и специальным навыкам, назначениям и / или выбору работы и социальным отношениям, характерным для среды проживания и работы, которые составляют социальное пространство, сформированное в компании наличием различных профессиональных категорий. Профессиональная идентичность состоит из информации, полученной до вступления в

Таблица 4.

Распределение населения по групповому духу в работе

\begin{tabular}{|c|c|c|}
\hline Групповой дух & КОЛИЧЕСТВО ОБРАЗЦОВ & (\%) \\
\hline ДА & 119 & $91,66 \%$ \\
\hline НЕТ & 11 & $08,33 \%$ \\
\hline ВСЕГО & 130 & $100 \%$ \\
\hline
\end{tabular}

Таблица 5.

Распределение опрошенных по важности отношений между коллегами

\begin{tabular}{|c|c|c|}
\hline Важность отношений & КОЛИЧЕСТВО ОБРАЗЦОВ & (\%) \\
\hline Важный & 100 & $20 \%$ \\
\hline Неважно & 20 & $10 \%$ \\
\hline Существенный & 10 & $100 \%$ \\
\hline ВСЕГО & 130 & \\
\hline
\end{tabular}

Распределение выборки по характеру отношений с руководителем

Таблица 6.

\begin{tabular}{|c|c|c|}
\hline Близкие отношения с поваром & КОЛИЧЕСТВО ОБРАЗЦОВ & (\%) \\
\hline ДА & 91 & $30 \%$ \\
\hline НЕТ & 39 & $10 \%$ \\
\hline ВСЕГО & 130 & $100 \%$ \\
\hline
\end{tabular}


профессиональную жизнь, а также из опыта и идей, приобретенных с момента поступления на рабочее место.

Профессиональная идентичность - это траектория, по которой человек постепенно развивается и совершенствует свои способности, планируя всю свою профессиональную деятельность.
Таким образом, профессиональная идентичность это сложный процесс, который создается, но развивается в течение всей жизни, эти фазы развития могут быть отмечены настоящими кризисами, во время которых профессионалы паразитируют внутриличностными конфликтами, которые тянут их между тем, кем они хотят быть. и какие они есть на самом деле, в зависимости от того, где они работают.

\section{ЛИТЕРАТУРА}

1. Gohier. Кристиана и другие. Преподаватель - обучение: построение профессиональной идентичности, исследования и обучение, Издание: L'Harmattan, Париж, 2000.

2. Sainsaulieu P., (1985), Идентичность на работе - эффекты культуры в организации - Нажмите National Science Foundation политики.

3. Альпе Ив и другие, Lexique de sociologie, Издание: Dalloz, Париж, 2007.

4. Дубар Клод. Социализация, 3-е издание, Арман Колин, Париж, 2000.

5. Дубар Клод. Социализация: построение социальной и профессиональной идентичности, Издание: Армон Колин, Париж, 1991.

6. Дубар, К. (1998а). Социализация. Построение социальной и профессиональной идентичности. Париж: Арман Колин.

7. Эдгар Шейн. Организационная культура и чип-лидер, Издание: Jossoy Basse, 1985.

8. Jodelet D., Безумие и социальные представления, Париж, Пуф, 1989.

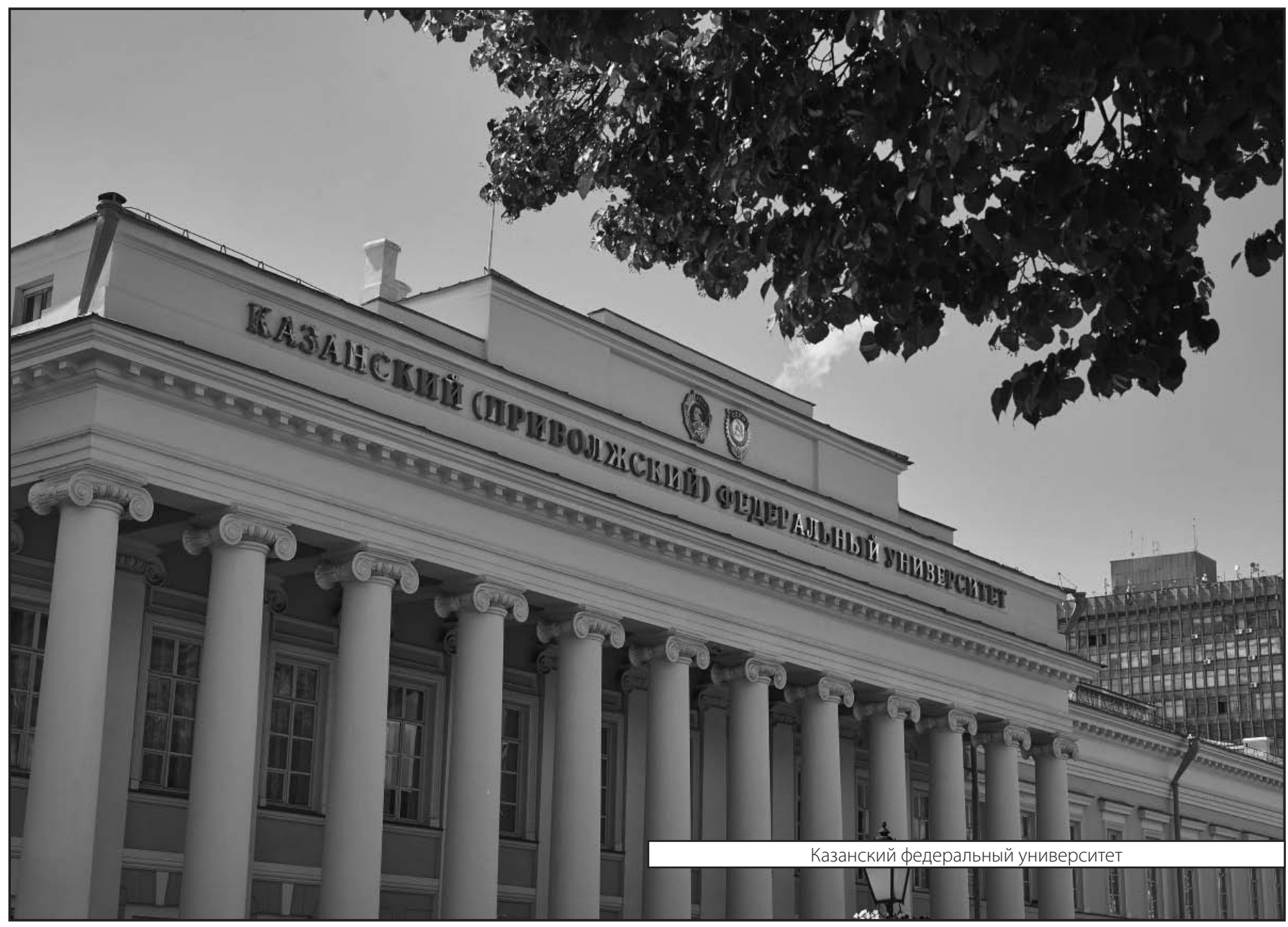

